\begin{abstract}
José Vicente Peiró Barco
Doctor en Literatura Hispánica por la UNED de Madrid, actualmente vinculado a la Unidad de Investigación de Literatura Hispanoamericana de la Universidad de Alicante. Especializado en literatura paraguaya, estudió la narrativa contemporánea de este país en su tesis doctoral, así como la obra de Roa Bastos en su memoria de licenciatura titulada Análisis de El Fiscal de Augusto Roa Bastos. Es autor de la edición crítica de la novela Mancuello y la perdiz de Carlos Villagra Marsal, para la colección «Letras Hispánicas» de la Editorial Cátedra, y de la antología Narradoras paraguayas junto al autor paraguayo Guido Rodríguez Alcalá, entre otras aportaciones al tema, además de artículos en revistas y de participar en congresos. Dirige el portal de literatura paraguaya de la $\mathrm{Bi}$ blioteca Virtual «Miguel de Cervantes» de la Universidad de Alicante. Actualmente, se encuentra a punto de editarse una recopilación de sus artículos más relevantes publicados en la prensa cultural paraguaya, prepara un estudio sobre la evolución de la narrativa paraguaya desde Yo el Supremo de Augusto Roa Bastos hasta el año 2000 y un acercamiento amplio a la poesía y al teatro paraguayo.
\end{abstract}

1

ROA BASTOS, Augusto: «La mú sica y el carácter nacional paraguayo». Asunción, Revista del Ateneo Paraguayo, 17, febreromarzo (1947)

2

Omitimos fechas de nacimiento $y$ defunción de los autores, para evitar que el lector se detenga en el dato, en lugar de prestar atención a las ideas. Para obtener cualquier dato se puede consultar Teresa Méndez-Faith: Breve diccionario de la literatura paraguaya. Asunción, El Lecior $\left(2^{\mathrm{a}}\right.$ edición), 1997. Se puede encontrar esta obra en el portal de literatura paraguaya de la Biblioteca Virtual «Miguel de Cervantes» (mww.cervantesvirtual.com).

3

AMARAL, Raúl: El modernismo poético en el Paraguay (19011916), Asunción, Alcándara, $2^{9}$ edición, 1982.

MARINI PALMIERI, Enrique: prólogo de Eloy FARIÑA NÚÑNEZ: Las vértebras de Pan, Asunción, Ediciones Ñandutí Vive / Intercontinental Editora, 1990, pp. 7-32.

Literatura paraguaya actual: poesía y teatro

JOSÉ VICENTE PEIRÓ BARCO

\title{
LITERATURA PARAGUAYA ACTUAL: POESÍA Y TEATRO
}

\author{
José VICENTE PEIRó BARCO
}

A Rudi Torga

Existe la certeza en el pensamiento de la intelectualidad paraguaya de que su país es tierra de poetas y no de narradores. A esta idea se ha añadido la continua afirmación de la carencia de tradición narrativa. Incluso se ha aludido a la ausencia de raíces populares de la poesía en español porque éstas pertenecen a la escrita o recitada en guaraní1. La poesía paraguaya actual se enfrenta a estos tópicos y a afirmaciones discutibles y cuestionables, y, sobre todo, a la inmensa hojarasca que la ha cubierto, dada la liviandad de una parte de las opiniones críticas y la inflación de poetas cuyas aportaciones son bastante limitadas y escasamente relevantes. Ante esta situación, cabría una interpretación que, sin desdeñar las aportaciones críticas anteriores, reordenara una visión de conjunto del género con un mayor grado de profundidad. En virtud de ello, se hace necesario un nuevo análisis de la evolución sustancial de la lírica paraguaya a lo largo de su historia.

Debemos comenzar por evaluar qué significa dentro de la historia y la evolución de la literatura paraguaya, imponiendo un criterio cronológico que nos permita adquirir una perspectiva amplia del mismo. La poesía ha sido el género literario por antonomasia en el Paraguay. De hecho, quien escribiera un poemario ya podía - y puede - ser considerado «autor literario», sin preocuparse en ocasiones por valores estéticos mínimos. La producción poética paraguaya, a lo largo de su historia, es notablemente superior a la de cualquier otro género literario, por lo menos hasta el último cuarto del siglo XX, quizá porque resultaba más cómodo y breve el dedicarse al verso como medio de expresión o por las mayores posibilidades de publicación dado el menor coste de las ediciones de obras líricas. De hecho, el gran autor de la literatura del país guaraní del siglo XIX es un poeta romántico-nacionalista cuyo tema dominante era el canto a las glorias de la patria como cronista del ejército del mariscal López durante la Guerra de la Triple Alianza (1864-1870): Natalicio Talavera ${ }^{2}$. Incursiones románticas al margen, la siguiente generación literaria paraguaya, la novecentista, se nutrió fundamentalmente de poetas y polemistas. Eugenio A. Pane, uno de los más destacados, demostró que el sentimentalismo se podía mezclar con la racionalidad de su generación. Los López Decoud, Juan E. O'Leary, Juansilvano Godoy o Ricardo Brugada, giraron la poesía hacia presupuestos más universales, pero sobre ellos acabó pesando el ambiente político nacional, lo que perjudicó notablemente a su inspiración $y$, por tanto, a sus temas y formas.

El Modernismo tuvo expresiones poéticas con peso específico en Paraguay. Los trabajos de Raúl Amaral y de Enrique Marini Palmieri así lo demuestran ${ }^{3}$. Se ha tenido en cuenta que el Canto Secular de Eloy Fariña Núñez ha sido su aportación más notable, pero son tanto o más modernistas las composiciones de Fortunato Toranzos Bardel. Parte de él desembocó en el llamado mundonovismo y en el nativismo, bien representados por el fortalecimiento de la poesía escrita en guaraní, sobre todo de la mano de Narciso R. Colmán, y por Natalicio González y Manuel Ortiz Guerre- 
ro, autor de bastantes letras de las guaranias que en los años veinte compusiera el músico José Asunción Flores. De ahí que mantengamos en vigencia las opiniones de Amaral y Marini-Palmieri mientras no aparezca otro nuevo estudio que ofrezca una nueva visión pormenorizada de toda la poesía paraguaya de las primeras décadas del siglo XX.

Durante estos años se aprecian temáticas universalistas como el anhelo de justicia en Gomes Freire Esteves, el metapoético con audacias estróficas en Guillermo Molinas Rolón, pero se imponen los versos amorosos, los panegiristas a los héroes de la historia paraguaya y los hímnicos en la mayor parte de ellos. La poesía, como el ensayo polemista o los géneros memorialísticos y autobiográficos, también participó de la revisión del pasado en tono nacionalista. El conjunto desembocó en la superación del Modernismo y de los temas neorrománticos para buscar un «más allá» sin alejarse de los problemas terrenales. Es la época que Raúl Amaral denomina Posmodernismo poético. La revista Juventud (1923-1926) atestigua estos cambios. Se abandona el gusto por la forma y se profundiza en los contenidos. Entre estos poetas - José Concepción Ortiz, Pedro Herrero Céspedes, Hérib Campos Cervera (padre), por citar algunos - destaca Julio Correa, que supo captar la esencia de la expresión paraguaya, mezcla de español y guaraní, para profundizar en el canto a los seres que sufren y el desvalimiento de las capas sociales más humildes.

Los atisbos de la vanguardia también necesitan una revisión. Generalmente, su influjo se ha retrasado hasta la llamada Generación del 40, en la que destacan Josefina Pla, Augusto Roa Bastos, Hérib Campos Cervera (hijo), Hugo Rodríguez Alcalá y Elvio Romero; la mayor parte, autores que emigraron por distintas circunstancias - políticas, económicas, profesionales y personales-, sobre todo a Argentina ${ }^{4}$. Heriberto Fernández escribió un poema vanguardista cuando residía en $\mathrm{Pa}$ rís en los años veinte, pero falleció poco después, mientras al Paraguay no llegaban esas nuevas corrientes que sí, en cambio, se recibían con fervor en Brasil y Argentina. Hubo contactos con algunos movimientos, como el creacionismo, pero no fructificaron en la práctica. La vanguardia afectó a la Generación del 40 cuando ya se imponían nuevos compromisos poéticos, como el social, cuyo represen- tante máximo es Elvio Romero. De hecho, el más considerado como renovador por influjo vanguardista, Campos Cervera, adquiere mayor tono en sus trabajos de temática social que por la práctica de procedimientos heredados de los «ismos», aunque su poesía rezume la humanización que se vislumbra en César Vallejo. De ahí que pensemos que la vanguardia no tenga hitos importantes en el Paraguay, al menos como los pueden tener otros países latinoamericanos, aunque existan muestras aisladas o influjos visibles en la poesía posterior a la década de los treinta, cuando presumiblemente las vanguardias entran en su ocaso. Se sigue cultivando una lírica más o menos tradicional formalmente, y los contenidos recogen temas amorosos, nacionales, sociales e intimistas preferentemente, hasta que la Generación del 40 irrumpe con la batalla por la renovación expresiva, en la que vence finalmente, sobre todo al mantener contactos con el exterior o proceder de fuera del país como es el caso de Josefina Pla. Será con esta generación cuando se inicie el camino de lo que denominaríamos poesía actual, motivo esencial de este trabajo, hecho además que se intensifica cuando pensamos en que algunos de estos autores están vivos y en activo, lo que les lleva a mezclarse con autores de apenas veinte años en el ámbito de la literatura paraguaya actual, en este tránsito de siglos.

Dejando al margen la labor poética de Roa Bastos, primeriza y augurio de su extraordinaria narrativa posterior, la poesía paraguaya posterior a 1940 más conocida es la de protesta social. Sobre todo Elvio Romero, cuyas obras Destino y atardecer (1962), Libro de la migración (1966) y Los innombrables (1974) son muestras de su mejor lírica. Su canto traspasa el Paraguay se hace eco de las preocupaciones latinoamericanas, razón que le permite conectar con la mejor poesía social del continente. Su importancia se percibe en que aparece en todas las selecciones de poesía paraguaya contemporánea, mientras el resto de autores incluidos varía.

Dentro del país, un amplio grupo de jóvenes se sienten atraídos por la lírica y se integra en la Academia Universitaria que dirige el sacerdote español César Alonso de las He-
HUGO RODRIGUEZ-ALCALÁ

\section{EL PORTÓN INVISIBLE}

4

La tesis más o menos establecida es la de Hugo Rodríguez Alcalá, en «El vanguardismo en Paraguay», Pittsburg, Revista Iberoamericana, $118-119$ (enero-junio 1982), pp. 241-255. 


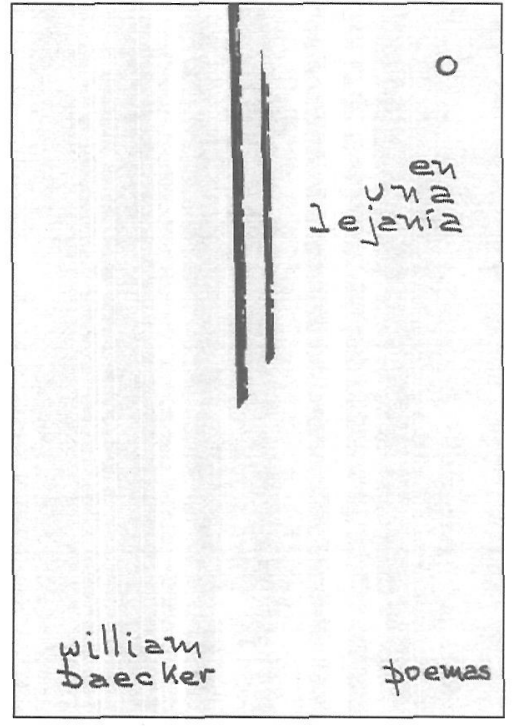

En una lejanía. Portada.

5 Roque VALLEJOS: La literatura paraguaya como expresión de la realidad nacional. Asunción, Editorial Don Bosco, 1971

Literatura paraguaya actual: poesía y teatro

JOSÉ VICENTE PEIRÓ BARCO ras, bajo la consigna de «la conquista del Paraguay por la cultura», a partir del último lustro de los años cuarenta. Entre ellos se encuentran los mejores poetas del segundo tercio del siglo: el mismo César Alonso, Ricardo Mazó, Rodrigo DíazPérez, Ramiro Domínguez, Carlos Villagra Marsal, José Luis Appleyard, Rubén Bareiro Saguier, Gustavo Gatti, Luis María Martínez, Elsa Wiezell, María Luisa Artecona de Thompson, Gonzalo Zubizarreta y José María Gómez Sanjurjo. César Alonso les inculcó el estudio analítico de los poetas españoles del 27 y de otras figuras como Antonio Machado y Juan Ramón Jiménez, y su influencia se hizo notar en los jóvenes autores. Es un segundo momento donde la lírica del país trata de situarse en consonancia con las corrientes recientes, sobre todo de España. Hay intentos próximos a la poesía pura, al compromiso estético mezclado con el social y el deseo de transmitir mensajes. Es la búsqueda de una nueva expresión nacional, aunque en realidad estos autores aprovechan lo nativo para hallar la universalidad de sus temas y formas. Se renuevan las formas y aprovechan el camino abierto por la Generación del 40, sobre todo en la ruptura de las formas tradicionales, aun con el respeto suficiente para cultivarlas cuando fuera necesario, pero no por imposición genérica, para encontrar una lírica más auténtica, sin corsés y libre de trabas impuestas por las necesidades nacionales o personales, sin huir de los compromisos personal y social.

Julio César Troche y Rubén Barreiro Saguier crearon la revista Alcor (1953-1960) que fue garantía de expresión de estos autores y de otros noveles que surgían con mayor frecuencia cada vez. Los poetas se inspiraban ahora en temas universales como el tiempo, la belleza, el conocimiento, la pasión por las causas nobles, el humanitarismo, la ruptura de espacios de enclaustramiento, la transcendencia del lenguaje y la pintura del objeto inanimado con las sensaciones que produce, pero no desde el punto de vista impresionista o simbolista, sino puramente conceptual. Pero sobre todo, en esos años se impone el testimonio de la violencia y el odio generados por las disputas políticas, mezclados con la orientación intimista y el tono melancólico de parte de las composiciones.

En los años sesenta, los jóvenes discurrieron en paralelo a los acontecimientos internacionales. Aumentó la intensidad de la lucha contra la dictadura de Stroessner. Ello obligaba a una poesía combativa, pero a la vez a versos que analizaran las causas del enclaustramiento que sentían. Hubo un mayor deseo de libertad en todos los ámbitos, que desembocó en una pronunciada audacia formal de una lírica vehículo de denuncia de la injusticia y de la tiranía. Los versos no escondían la asfixia de los autores ante una situación agobiante hasta la claustrofobia y transmitían la angustia por el estado del país y su aislamiento. La poesía, de la misma manera que desde finales del siglo XIX hasta los años treinta del XX había sido útil para ensalzar la realidad nacional y crear una ideología patriótica perdurable, a partir de los sesenta era el instrumento idóneo para expresar el disgusto: con la sociedad, con la política... y con uno mismo. Nunca ha habido en Paraguay una lírica tan personal como la surgida a partir de estos años, cuando, en apariencia, la social predominaba.

Las revistas continuaron siendo el vehículo estelar para la divulgación lírica. Alcor proseguía su afianzamiento, mientras se editaban otras que, sin romper con sus postulados, ofrecían sus discrepancias de raigambre juvenil. De ellas hay que destacar Diálogo y Criterio (1966-1971). Miguel Ángel Fernández fundó la primera y en la segunda participaron José Carlos Rodríguez, Adolfo Ferreiro, Juan Manuel Marcos, Emilio Pérez Chaves, René Dávalos, Nelson Roura y otros. En todos ellos se percibe la angustia interior y la continuidad con los poetas precedentes. Quizá esta década sea una de las más fructíferas del siglo, dada la aparición, además de los susodichos, de obras líricas firmadas por Esteban Cabañas, Gladys Carmagnola, Raquel Chaves, Ovidio Benítez Pereira, Rudi Torga, Jacobo Rauskin, Osvaldo González Real, Francisco Pérez-Maricevich o Roque Vallejos. De todos ellos destaca como denominador común el que preconicen una poesía política y socialmente significativa, pero siempre, profundizando en la expresión de los autores anteriores, subrayando el negativismo, al decir de Roque Vallejos ${ }^{5}$. Las formas se simplifican, porque los autores abogan por el verso simple; por la esencia, en suma. 
En los setenta, el afianzamiento del régimen de Stroessner, favorecido por la aparición de dictaduras militares semejantes en los países vecinos, provocó el incremento de la represión. Como consecuencia, la poesía sociopolítica adquiere mayor protagonismo. El régimen no ve aún excesivamente como enemiga a la literatura y permite, hasta cierto punto, licencias que entenderá como fruto de los ociosos. Pero siempre pesará como una espada la autocensura sobre los autores. Se percibe el miedo y el deseo de encriptar los mensajes, ya por la vía del experimentalismo (Jorge Canese), ya por medio de la sugerencia implícita. El odio a la tiranía se percibe en obras como la de Guido Rodríguez Alcalá. Pero tampoco abandonan temáticas como el amor, en el caso de Miguel Ángel Caballero Figún, Aurelio González Canale o William Baecker, pero casi siempre en tono melancólico. Otros motivos son la evocación de la infancia (Juan Manuel Marcos) o la noche como símbolo de desconcierto (Víctor Casartelli). A la par, Renée Ferrer hace gala de una poesía intimista, de la voz de la mujer heredada del grito de Josefina Pla.

A finales de los setenta, se creó el Taller de Poesía «Manuel Ortiz Guerrero». Lo integraron Jorge Gómez Rodas, Moncho Azuaga, Jorge Aymar y Mario Rubén Álvarez. A ellos se fueron sumando nuevos poetas jóvenes (Miguel Ángel Meza, Augusto Casola, Ramón Silva, Victorio Suárez, Delfina Acosta, Ricardo de la Vega, Santiago Dimas Aranda, Amanda Pedrozo, Mario Casartelli, Pedro Céspedes, Susy Delgado y Mabel Pedrozo, todos nacidos a partir de 1950, salvo Aranda) que defendían el tomar contacto con las clases populares por medio de la poesía, para lo cual tomaron como primer objetivo el integrar el guaraní en su expresión lírica personal, y no sólo para narrar en verso o cantar la excelsitud del país, como ocurría hasta entonces. Creían en una poesía capaz de superar la dificultad de edición, por medio de la presentación de trabajos colectivos, pero siempre contando con el carácter individual de la creación, como un acto particular, aunque ligado siempre a la función social.

En los ochenta se produce un auge de la narrativa. Pero la poesía también experimenta un nutrido aumento de publicaciones. NAPA incorporó a sus colecciones de narrativa, una de poesía, donde destacan La llama y la arena de Josefina Pla o Leviatán etcétera de Guido Rodríguez Alcalá. Sin embargo, es en 1984 cuando surge el primer intento ejemplar de reunir la mejor poesía paraguaya: la colección Alcándara (1982-1987)6. Se convirtio en una verdadera «enciclopedia» de la lírica paraguaya. Incluyó a casi todos los autores más destacables, desde los de antaño como Martín de Goycoechea Menéndez (aunque no olvidemos que es argentino, pero la historiografía literaria paraguaya se lo apropia por haber vivido en el país y reflejar sus escenarios en las obras), Juan E. O'Leary y Alejandro Guanes, pasando por la generación del 40 (Roa Bastos, Josefina Pla, Hérib Campos Cervera, Elvio Romero y Hugo Rodríguez Alcalá), los poetas en plena madurez y los más jóvenes como Juan Manuel Marcos, Nila López o Susy Delgado. Alcándara fue un estímulo para los poetas, que ya no dejaron de publicar sus obras escritas, y, sorprendentemente, los editores obtuvieron beneficios económicos con ella.

Frente a las mayores posibilidades de edición, en cambio, las dificultades frente a la censura dictatorial aumentaron. Si hasta entonces el régimen de Stroesser había sido permisivo, hasta cierto punto, con el género, en 1982 prohibió con firmeza el poemario Paloma blanca, paloma negra de Jorge Canese, por incluir la expresión «este país de mierda». La prohibición afectó incluso al acto de la presentación del poemario, puesto que se suspendió por la expulsión del país de Augusto Roa Bastos, que había viajado para presentarlo, aunque finalmente se realizó por la valentía de Francisco Corral, director del Centro Cultural Juan de Salazar de la Embajada de España. El fantasma de la represión no impidió que con Alcándara se publicaran autores mal contemplados por el régimen, o que incluso las obras de Elvio Romero fueran declaradas de utilidad pública, tremenda contradicción. Al fin y al cabo, las obras secuestradas y prohibidas podían adquirirse en algunas comisarías, aunque a un precio más elevado.

A partir de Alcándara, la situación fue más halagüeña y proliferaron las colecciones poé-
6

Fundada por Carlos Villagra Marsal, José María Gómez Sanjurjo y Jorge Gómez Rodas.
Literatura paraguaya actual: poesía y teatro

JOSÉ VICEN'TE PEIRÓ BARCO 
ticas en algunas editoriales, hasta la actualidad. La caída de la dictadura provocó el nacimiento de una «poesía de alivio», que denunciaba y manifestaba un optimismo, a la vez, que con el tiempo se fue desvaneciendo a la luz del desencanto de la transición democrática. Jacobo Rauskin es uno de los exponentes de esta evolución. A la vez, surgían nuevos talleres, aunque más pedagógicos y sin el ánimo editorial del «Ortiz Guerrero», de donde nacieron nuevos poetas, sin distinción de edad. Poco a poco van predominando los temas intimistas y personales, y aunque la crítica social o política no se esfuma completamente, sí que no se desarrolla tan ampliamente. A la vez, el romance histórico adquiere vigor con Hugo Rodríguez Alcalá y Delfina Acosta. Y a finales de los noventa irrumpe en escena la autodenominada «Generación del 90», que surge de los universitarios de Humanidades. Centran su actividad en tertulias, recitales, contactos entre grupos literarios e incluso un manifiesto para alegar que la literatura no ha muerto. El libro colectivo El ombligo del mundo reunirá a noventa y nueve autores jóvenes, con el apoyo de los poetas consolidados Joel Filártiga, Emilio Pérez Chaves, Miguel Ángel Fernández, Luis María Martínez y Jorge Aiguadé. De estos autores jóvenes, hay dos a destacar: Saskia Saer y Marcelo Sarubbi, que caminan por una poesía vivencial e interrogativa. Los nuevos nombres (Rick Taylor, Iván González, Nelson Aguilera, Raquel Rojas, Lía Colombino, José Antonio Alonso, Moneca Laneri y Diana Villaverde) aportan frescura y temas de lo cotidiano. El tiempo los examinará.

Hemos dejado un apartado específico para la poesía escrita por mujeres, por la especificidad que ofrecía hasta la aparición de un amplio conjunto de autoras a partir de la década de los ochenta del siglo XX. También en la poesía, la mujer nunca ha estado ausente de su cultivo, pero siempre ha tenido que vivir la postración y la marginalidad, a pesar de que las autoras generalmente solían pertenecer a capas sociales ciertamente acomodadas. El primer poema publicado por una mujer, que se recuerde e la actualidad, es "La pecadora», de Marcelina Almeida, autora de posible origen uruguayo, que se incluyó en la revista $\mathrm{La}$ Aurora (1860) dirigida por Ildefonso A. Bermejo. Se recuerda el romanticismo de « $\mathrm{Al} \mathrm{Pa-}$ raguay» de Ercilia López de Blomberg, los poemas que Serviliana Guanes, Josefina Sape- na Pastor (Blanca Lila), Enriqueta Gómez Sánchez e Inés Marsal publicaron en la prensa entre principios de siglo y la guerra del Chaco, el gusto afrancesado de Ida Talavera de Fracchia (próxima a la generación modernista de la revista Juventud, 1923), el nativismo intimista de Renée Checa en la década de los veinte, y la poesía erótica de Dora Gómez Bueno de Acuña, desde los años cuarenta. Ellas dieron una continuidad, minoritaria pero consistente, a la participación femenina en la evolución de la lírica paraguaya.

Pero por encima de todo está la labor de Josefina Pla, que evolucionó desde el posromanticismo de El precio de los sueños hasta la poesía existencial y vivencial de La llama y la arena (1987), pasando por la ruptura formal heredada de la vanguardia. Su poema «Piedra», contenido en esta obra, encierra el anuncio de la lucha y la postración que sufrió a lo largo de su vida por el hecho de ser mujer. pero siempre había ocupado un segundo plano hasta la aparición de Josefina, quien rompe con los esquemas sociales tradicionales. Prueba de su herencia e importancia es el testimonio de las autoras actuales más jóvenes, que se declaran herederas del espíritu de Josefina Pla.

Años más tarde, María Luisa Artecona de Thompson y Elsa Wiezell se implicaron en la Academia Universitaria dirigida por César Alonso, a la que hemos aludido. Ellas abogaron por la poesía de la psicología femenina y como refugio frente a la marginación social a que les empujaba el mundo público. En paralelo, Ester de Izaguirre publica sus primeros poemas en la revista Alcor, antes de emigrar a Argentina, donde residirá hasta hoy en día y cultivará predominantemente poesía existencial.

$Y$ las generaciones siguientes fueron incrementando el número de mujeres dedicadas a la lírica: Noemi Ferrari de Nagy, Carmen Soler, Gladys Carmagnola, Renée Ferrer, Maybell Lebrón, Nilsa Casariego, Leni Pane, Miriam Gianni, María Elina Pereira de Olmedo, Raquel Chaves, Lilian Stratta, María Eugenia Garay, Susana Riquelme, María Carmen Paiva, Elinor Puschkarevich, Nidia Sanabria... tantas que resulta casi imposible realizar un inventario completo dada la dispersión de su obra. La siguiente generación ofreció un conjunto de autoras que acentuaron su defensa de la libertad de la mujer e intensificaron el ero- 
tismo y la sensualidad. Algunas destacan por el uso de la ironía para satirizar al hombre y su dominio social. Ejemplos son Susy Delgado (autora de poemarios bilingües), Carmen Casartelli, Amanda Pedrozo, Nila López Lourdes Espínola o Delfina Acosta, que cultiva también poesía laudatoria a su pueblo o a Pablo Neruda. La última poesía incide en lo misterioso y en la vida cotidiana, y en el caso de Montserrat Álvarez en la noctunidad como ocurre en Zona dark y Underground, obras de atmósferas viciadas y ocultas a la vida que es noticia de prensa, como cantos a la libertad que permite la noche.

Un espacio, antes finalizar, merece la poesía en guaraní. Generalmente recitativa, predilecta para el caso (Juan Maidana), se adentra en temáticas más universales y va abandonando el localismo. Destaca el intimismo de Feliciano Acosta, Susy Delgado y Miguel Ángel Meza, la nostalgia de Rudi Torga, el lamento ante los problemas nacionales por medio de un ejercicio expresivo minimalista de Zenón Bogado Rolón, la inquietud social de Eulogio Zárate, el amor y el canto a la libertad de Lino Trinidad Sanabria, la ironía social crítica y el alumbramiento del estallido popular de Ramón Silva, y el canto social e indigenista de Félix de Guarania. Lo más importante no sólo es la amplitud temática que ha ido adquiriendo la poesía en guaraní desde finales de los setenta, sino el tratamiento expresivo innovador, personal, lo que ha provocado que los autores alcancen la perfección formal de los que escriben en español. De hecho, en la clasificación que desarrollamos para culminar este artículo, no hemos separado los autores en guaraní del resto, dada la similitud temática y formal que se aprecia en todos ellos, porque sólo se diferencian por la lengua empleada, y ya no por los temas.

Por sintetizar este breve recorrido, en la poesía paraguaya actual, donde conviven distintas generaciones, desde la llamada de los 40, hasta los más jóvenes que apenas sobrepasan los veinte años, hallamos varias tendencias que enumeramos':

1) Poesía minimalista (William Baecker y Zenón Bogado Rolón)

2) Poesía experimental (Jorge Canese, Joaquín Morales, Jorge Montesino)

3) Poesía sociopolítica (Gilberto Ramírez Santacruz, Elvio Romero, Luis María Martínez, Moncho Azuaga)
4) Poesía reflexiva (José Luis Appleyard, Manuel E. B. Argüello, Rubén Bareiro Saguier y Juan Manuel Marcos)

5) Poesia de reivindicación femenina (René Ferrer, Gladys Carmagnola, Susy Delgado, Delfina Acosta)

6) Neoimpresionismo nativista (Carlos Villagra Marsal, José Antonio Bilbao)

7) Poesía existencial (Augusto Casola, Ester de Izaguirre, Guido Rodríguez Alcalá)

8) Indigenismo (Félix de Guarania, Santiago Dimas Aranda, Ramiro Domínguez)

9) Poesía amorosa (María Elina Pereira, Ricardo de la Vega, Ester de Izaguirre)

10) Poesía erótica (Renée Ferrer, Nila López, Lourdes Espínola, Amanda Pedroso)

11) Poesía intimista (Gladis Carmagnola, Nilsa Casariego, María Eugenia Garay, Maybell Lebrón, Elinor Pushkarevich, Feliciano Acosta)

12) Poesía de la experiencia (Jacobo Rauskin, Ricardo de la Vega, Víctor Casartelli, Francisco Pérez Maricevich, Moncho Azuaga)

13) Poesía mítica (Raquel Chaves, Ramiro Domínguez)

14) Poesía oscura (Montserrat Álvarez)

15) Poesía expresiva-interrogativa (Marcelo Sarubbi, Saskia Saer)

16) Romance histórico (Hugo Rodríguez Alcalá y Delfina Acosta)

17) Poesía infantil (Nidia Sanabria, Renée Ferrer, Elly Mercado de Vera, Feliciano Acosta).

Este ensayo clasificatorio demuestra la riqueza de tendencias de la poesía paraguaya actual. Obviamente, los autores discurren por varias de ellas a lo largo de su trayectoria, aunque los hemos ubicado en una donde destacan. Un autor no ofrece una obra monocorde, por lo que no se le debe encasillar en esta clasificación. Son necesarios nuevos acercamientos con criterios que la escasa perspectiva temporal de que disponemos nos impide hallar. Lo cierto es que la poesía paraguaya muestra una riqueza singular y una proliferación de obras publicadas desde los ochenta sin parangón a lo largo de su historia. Ha superado tópicos, y sin abandonar sus raíces, ha adquirido mayor amplitud temática, como la narrativa, y se ha convertido en un medio de expresión universal.

\section{ESENCIAS DEL TEATRO PARAGUAYO ACTUAL}

El teatro en Paraguay posee raíces ancestrales. Su origen se remonta a la dramatización
Citamos sólo hasta cuatro autores por cada tendencia para evitar que la nómina sea interminable. 
Rudi TORGA: "A modo de introducción: reflexiones en torno al teatro paraguayo de ayer y de hoy». En Teresa MÉNDEZ-FAITH edit.: Tearro paraguayo de ayer y de hoy. Asunción, Intercontinental Editora (Tomo 1), 2001, págs. 15-44.

\section{9}

Teresa MÉNDEZ-FAITH: Breve diccionario de la literatura paraguaya, Asunción, El Lector $\left(2^{g}\right.$ edición), 1997, pág. 255.

10

Lastimosamente, buena parte de los documentos teatrales paraguayos no han llegado a nosotros. Este material fue expurgado en determinadas épocas de los archivos de Asunción, hasta el punto de que desaparecieron muchísimas obras y documentos.

11

Para examinar la labor de Fernando Oca del Valle, ver mi artículo «Teatro paraguayo contemporánea: Fernando Oca del Valle». Valencia, Sticomythia, Universidad de Valencia, $\mathrm{n}^{\circ} 0$ (arrículo nำ7), enero 2002.

Literatura paraguaya actual: poesía y teatro

JOSÉ VICENTE PEIRO BARCO de las danzas rituales que ejecutaban los aborígenes en la selva, cuyo objetivo era la reconstrucción de la armonía de los seres con su comunidad y con la naturaleza, como expresa Rudi Torga ${ }^{8}$. Era una teatralización religiosa repleta de simbolismos.

Los conquistadores españoles aprovecharon esta «afición» ceremonial para adoctrinar a los aborígenes guaraníes. El teatro fue un instrumento de propaganda muy útil para ellos. El adocenamiento solía fundamentarse en la escenificación de historias bíblicas, vidas de santos, la pasión de Cristo y las representaciones del Corpus Christi. Estas escenificaciones se atestiguan desde el último tercio del siglo XVI, sobre todo en los recintos de las misiones, que dieron lugar al conocido como teatro jesuítico (1607-1767). Fuera del ámbito religioso, según Torga, el teatro colonial no dejó una herencia con peso específico.

El siglo XIX no nos lega testimonios de grandes eventos dramáticos. Sí es cierto que se celebraron representaciones. De antes del final de la Guerra de la Triple Alianza, en 1870, destaca Un paraguayo leal del español Ildefonso A. Bermejo, obra compuesta al calor protector del gobierno de Carlos Antonio López, de carácter romántico y panegirista. El teatro resistió los avatares con tenacidad, igual que otros géneros como la narrativa. Y simplemente resistió. Los textos no vieron la luz y tampoco se recuerdan las representaciones en la prensa de la época, como se desprende de la laguna que muestran los textos críticos de carácter arqueológico que existen. De hecho, sólo se menciona un estreno, La cámara oscura de Alejandro Guanes, y con disparidad entre la crítica, que tildó la obra de escabrosa y de dudoso gusto, y el público, que aplaudió unánimemente la representación. Este estreno es de 1899. Antes, el desierto.

El teatro se encauza en Paraguay y se moderniza a partir de la década de los años veinte del siglo XX. Según Torga, arranca en 1922, con El crimen de Tintalila de Manuel Ortiz Guerrero, y otras obras de ese año y los siguientes como La chispa robada y Mboraybu ha tesay de Francisco Martín Barrios, La epopeya del mariscal de Eusebio Aveiro Lugo, La inquisición de oro de Leopoldo Ramos Giménez, Guavirami de Benigo Villa, Juguete roto de Facundo Recalde, Sorprendidos y desconocidos de Luis A. Rufinelli, La marca de fuego de Arturo Alsina y Mboraybu paba de Félix
Fernández. Estas obras dan un giro a la exigua escena en guaraní y en español. Son aceptadas por el público porque incorporan motivos populares y temas de la vida cotidiana. Arturo Alsina, por citar uno de los más relevantes, se sumerge en la decadencia de la clase dominante desde tesis ideológicas naturalistas.

El teatro paraguayo sufrió una renovación importantísima a partir de los años treinta con la aparición de Julio Correa. Como consecuencia de ello, en el ambiente de los años cuarenta había dos grupos claramente distinguidos. Por un lado se situaba la corriente de José Arturo Alsina, partidario de un teatro universal, que sin huir de lo particular no cayera en el folclorismo, y cuyo drama de resonancias pirandellianas, al decir de Teresa Méndez-Faith', El derecho de nacer (1925), es el mejor ejemplo de su creación; por otro, la del teatro en guaraní, o al menos con un empleo importante de esta lengua, cuyos antecedentes se remontan a algunos de los autores susodichos de 1926, cuya expansión y éxito llegaría en la década de los treinta con Julio Correa, considerado por los críticos como el impulsor del teatro marcadamente popular, cómico, que tendía a la oralidad, a la técnica intuitiva y a los condicionamientos lingüísticos ${ }^{10}$. Este autor impulsó una suerte de teatro que llegaba mayoritariamente al público por el simple motivo de que reproducía temas de preocupación popular y la situación oral bilingüe del país. Los asistentes a las representaciones entendían sus obras, por el componente decisivo de esta lengua, y participaban en ellas en mayor grado que en las puestas en escena de obras de otras vertientes, ya que, generalmente, el conjunto del teatro paraguayo de esa época se encontraba bastante anquilosado en un posromanticismo vacuo y en procedimientos con olor a naftalina, a pesar de los intentos de Alsina. Es importante, además, porque se percibía un fondo social con el que sintonizaba el público.

En los años cuarenta del siglo pasado, Roque Centurión Miranda y otros nombres emprendieron la renovación definitiva del teatro paraguayo y se acercaron a las instituciones con el fin de asentarlo. En esta renovación participaron dos españoles, sobre todo en el ámbito pedagógico: Josefina $\mathrm{Pla}(1903-1999)$ y Fernando Oca del Valle (1893-1972) ${ }^{11}$. La actividad dramática contaba con el apoyo del Ateneo Paraguayo y de la Escuela Municipal 
de Arte Escénico, fundada por Centurión en 1948. Josefina Pla y Roque Centurión trabajaron juntos, como en los dramas Desheredado y Aqui no ha pasado nada. La importancia de ambos radica en su intento por mostrar una escena más sofisticada y con atención a temas universales y problemas generales, dejando en un segundo plano, aunque nunca abandonado completamente, el elemento popular o la preocupación por la lengua a utilizar. El tema del conflicto de la paternidad responsable frente a la doble moral de la sociedad de Aquí no ba pasado nada es el mejor ejemplo del camino de ambos autores. En esa década, se inicia la publicación de obras teatrales por parte de la Imprenta Nacional.

La tarea docente y tallerística prosigue y se crea un elenco de actores que, a pesar de que no terminan con algunos tics completamente, como la grandilocuencia y la rimbombancia de la dicción, pone las bases de la escena actual. El número de autores aumenta y particularmente adquiere notoriedad el teatro de reparto. Aumenta la representación de clási$\cos$ y autores vivos españoles, junto a los paraguayos, favorecidos por la proximidad de algunos exiliados. Ello acerca la situación del teatro del país a la de sus vecinos. Se puede afirmar que las formas interpretativas de Margarita Xirgu también influyeron en los actores.

Pero vayamos a los hitos más representativos del teatro paraguayo actual. La comedia social tiene como principal representante a Néstor Romero Valdovinos, quien desde Buenos Aires, supo captar la esencia del sufrimiento de los hombres paraguayos. Su obra Mbokaja ba'eño (Cocotero solitario) fue uno de los textos más representados en los años setenta. Es el verdadero continuador de la comedia de Julio Correa, desde la profundidad de contenidos y conocimiento maduro del oficio dramático.

A partir de los sesenta, Mario Halley Mora se convierte en el autor con mayor éxito en la escena contemporánea, no solamente desde el punto de vista del número de seguidores entre el público, sino por aprovecharse, como creador, de su posición dentro del régimen de Stroessner. Se le puede considerar como el dramaturgo más comercial. Su prolífica producción suma más de sesenta títulos, de dispar calidad. Como su narrativa, Halley Mora examina la realidad que contempla, la introduce en argumentos atractivos para el público, y presenta personajes humanos y de vivencias palpables. Sea cómica o trágicamente, siempre existe una visión crítica del materialismo al que ha llegado la sociedad, y su visión suele ser escéptica ante la infravaloración del hombre.

El tema político va adquiriendo mayor empaque a medida que aumenta la represión de Stroessner. Los dramaturgos lo cultivaban, sobre todo los exiliados, como es el caso de Hérib Campos Cervera. Pero desde finales de los cincuenta es difícil encontrarlo sin que recurra a símbolos o alegorías que encubran la denuncia. Ocurre en las obras de Ovidio Benítez Pereira. Algunos exiliados, en cambio, son más directos en la crítica, como Carlos Garcete, autor de La caja de fósforos. José María Rivarola Matto prefirió penetrar en la crítica del poder y del despotismo desde la reflexión y la sensibilidad, con obras como $S u$ señoría tiene miedo o El fin de Chipi González. Pero en esta obras destaca también el ingenio y el buen sentido del autor, frente a la seriedad habitual que domina en el tratamiento del tema político.

El teatro de vanguardia e independiente anticipa sus frutos a partir de la década de los sesenta. Osvaldo Dragún fue uno de los impulsores, adoptando precedentes del grotesco y del absurdo. Muchas veces instrumento de resistencia cultural en la dictadura de Stroessner, desde la innovación textual, prosigue con la ruptura de los elementos paratextuales. Ello hasta desembocar en el teatro callejero, cuya figura principal es Moncho Azuaga, autor de Los niños de la calle, que supo sacar a los espectadores de las salas para denunciar la falta de compromisos sociales auténticos. Luis Hernáez también ha sacado la escena a la ca1le. De su evolución nos dará cuenta la estudiosa Edda de los Ríos más adelante. Pero no hay que obviar que del teatro independiente han surgido autores importantes y directores de relieve como José Luis Ardissone y Raquel Rojas.

Particular expansión ha experimentado el teatro histórico desde los años setenta. Vino favorecido por el ánimo de criticar y examinar el presente partiendo del pasado. En el caso de Ramiro Domínguez, con Cantata beroica a Pedro Juan Caballero (1972), superó el historicismo para penetrar en las raíces del teatro poético. Muy recurrente fue el tema del ma-
Literatura paraguaya actual: poesía y teatro

JOSÉ VICENTE PEIRÓ BARCO 
Como nos explicó Edda de los Ríos, y hemos podido constatar, González Delvalle surge en los años sesenta como autor de zarzuelas paraguayas y madura en los 70 convirtiéndose en dramaturgo de hecho al incorporarse al grupo Aty Ñeé. Escribe las primeras obras de su nueva época con Antonio Carmona y juntos realizan las primeras versiones de Brecht. Su incorporación al drama histórico se produce cuando ya ha adquirido una amplia experiencia teatral. riscal López. La agonía del héroe (Francisco Solano López o el valor moral) de Efraín Enríquez Gamón (1975) es un ejemplo. Era una defensa del presunto valor moral de López, como símbolo de todo un pueblo. Este autor formó en el curso de los años una Tetralogía paraguaya. Pero, sin duda, las obras más impactantes sobre el conflicto fueron las de Alcibiades González Delvalle ${ }^{12}$ : Elisa, San Fernando y Procesados del 70. Trató de dar una dimensión humana a los héroes, deformados por la historia oficial. El autor cuestiona el retoricismo patrioterista, al contrario que Enríquez Gamón, y despierta un proceso a quienes fueron los protagonistas de la historia paraguaya. Sin embargo, el fondo escondía una crítica a la dictadura, que así lo entendió y emprendió una campaña contra la obra San Fernando, alegando que difamaba al mariscal y su antiparaguayidad, hasta prohibirla en diferentes ocasiones (incluso la prohibió Rodríguez en plena transición democrática).

Héctor Micó explora la realidad nacional desde la historia convertida en farsa política. Gloria Muñoz, autora plenamente dedicada al mundo dramático, escenificó Almirante de sueños y vigilia, que plantea el asunto de qué punto de vista emplear para examinar la historia, con el pretexto de la vida de Colón, para proclamar la necesidad del retorno a las raíces históricas. Esta autora adaptó la novela Yo el Supremo de Augusto Roa Bastos a la escena.

Este autor, toma este mismo sentido, en $\mathrm{La}$ tierra sin mal, donde reproduce la dialéctica entre jesuitas e indígenas, con el fondo de la utopía que expresa el título. Situada en 1767, año de la expulsión de la orden, nos muestra otra dicotomía: el «ser» y el «tener».

En los años ochenta aumenta el número de autoras dedicadas a la escena. El mayor intimismo y los problemas femeninos adquieren mayor presencia. En los años cincuenta, habían destacado Concepción Leyes de Chaves, Josefina Pla, Mariela de Adler y Gilda de Fretes. Pero en los ochenta, la mujer aprovecha la escena para mostrar sus preocupaciones. Además de la susodicha Gloria Muñoz, los dramas de la vida adquieren vigor en autores como Pepa Kostianovky. Renée Ferrer apuesta por el tratamiento poético de la puesta en escena de los problemas, sobre todo femeninos, como en La colección de relojes. Edda de los Ríos, también formidable actriz que ha conducido al teatro paraguayo a escenarios de todo el mundo, transforma el vacío de la cotidianidad en problemática que alcanza los límites de la tragedia, con obras como $Y$ abora... ¿qué? y Kuña rekove.

Dentro del proceso de «intimización» de la escena paraguaya, Agustín Núñez penetra en los conflictos humanos y ámbitos sociales y familiares, como en Domingo de fútbol o Arroz con leche, aunque también es conocido por sus adaptaciones escénicas de Hijo de Hombre de Roa Bastos, Pedro Páramo de Rulfo y Un señor muy viejo con unas alas enormes de García Márquez, todas estrenadas.

El teatro en guaraní, cada vez más representado, tiene su estandarte en la obra de Félix de Guarania, quien se inspira generalmente en motivos populares. A finales de los setenta, un juez de la era stronista, Antonio Escobar Cantero, compuso una obra sorprendente titulada Tekojojá, al haber sido escrita por un autor con un cargo importante dentro del sistema, que denunciaba los abusos y arbitrariedades de la justicia durante esos años. La obra estaba escrita en un guaraní muy cerrado, y aún se representa de cuando en cuando en la escena paraguaya actual.

Mario Santander es el mejor representante de los autores que comenzaron a escribir y estrenar textos en los años noventa. Teatro de problemática urbana, enfoca inquietudes que parten de la vida cotidiana para reflejar el desconcierto actual. Formado en estudios teatrales estadounidenses, fue el impulsor y director del texto de creación colectiva titulado Mujeres, compuesto de diez breves partes, estrenada en 2001.

Hasta aquí el breve, e intenso, recorrido por la trayectoria del teatro paraguayo a través de su historia. Salvadas grandilocuencias y retoricismos de antaño, presenta un panorama cada vez más amplio, no sólo en autores, sino en elencos importantes y directores conocedores del oficio, como José Luis Ardissone, Raquel Rojas o el recientemente fallecido Rudi Torga, o los citados como autor, Mario Santander y Agustín Núñez, y la labor investigadora de Edda de los Ríos.
Literatura paraguaya actual: poesía y teatro

JOSÉ VICENTE PEIRO BARCO 